\title{
La colección de cartografía náutica del Real Observatorio de la Armada
}

Francisco José González González, Real Instituto y Observatorio de la Armada

En 1783, Vicente Tofiño (1732-1795), director de la Academia de Guardias Marinas, fue nombrado por el Gobierno jefe de una comisión hidrográfica integrada por oficiales de la Armada cuya misión sería el levantamiento cartográfico de las costas españolas. Los resultados obtenidos por la mencionada expedición, plasmados en el Atlas Marítimo de España y en los derroteros del Atlántico y del Mediterráneo, pueden ser considerados como una de las aportaciones fundamentales en la historia de la cartografía española.

No obstante, el esfuerzo hidrográfico español del XVIII no terminó ahí. Fueron muchas las expediciones de los últimos años del siglo XVIII en las que los marinos formados bajo la supervisión de Tofiño llevaron a cabo importantes trabajos hidrográficos, convirtiéndose en verdaderos exploradores de costas y territorios de los que en Europa se poseian aún escasos conocimientos. En 1797, ante la necesidad de organizar todo lo relacionado con los cada vez más numerosos trabajos hidrográficos, la Armada creó en Madrid la Dirección de Trabajos Hidrográficos, que incluyó entre sus funciones las correspondientes al Depósito Hidrográfico creado en Madrid unos años antes (1788). Esta nueva institución puede ser considerada como la primera dedicada oficialmente en España a la planificación, organización y publicación de trabajos cartográficos.

En todos estos trabajos hidrográficos, la colaboración del Real Observatorio de la Marina fue esencial y se produjo en dos vertientes. Por un lado, mediante la participación en dichos trabajos de su propio personal o de oficiales con preparación científica adquirida en el llamado curso de estudios mayores. Por otro lado, mediante el préstamo de instrumentos a las expediciones hidrográficas o la supervisión de la adquisición de los aparatos no disponibles en el propio Observatorio.

En los últimos años del siglo XVIII, la Armada intentó crear en la Isla de León un gran centro dedicado a las ciencias relacionadas con el mar. La propuesta oficial, aprobada definitivamente en 1792, pretendía construir un edificio que albergase una biblioteca general, una colección de instrumentos náuticos y una colección de materiales hidrográficos y cartográficos, además de gabinetes de Fisica y Química, de historia natural y de construcción naval. El oficial de la Armada José de Mendoza y Ríos recibió la orden de trasladase a París y Londres con objeto de adquirir libros, cartas e instrumentos con destino al mencionado centro. La comisión de Mendoza dio lugar al envío de numerosos materiales hacia Cádiz y se prolongó hasta febrero de 1796, fecha en la que la Armada abandonó oficialmente la idea de crear el mencionado centro. Algunos años después, la mayor parte de los libros y mapas enviados a España por Mendoza pasaron a engrosar los fondos del Real Observatorio y de la Dirección de Trabajos Hidrográficos.

A partir de 1859, el Observatorio de San Fernando contaría con una Sección de Geografía, encargada de todo lo relacionado con la aplicación de la Física y de la Astronomía a la Geografía y la navegación. Entre las funciones de esta nueva sección estuvieron la custodia, conservación y arreglo de los cronómetros de la Marina, de los instrumentos de Astronomía náutica, de Física y de Geodesia destinados a los servicios de la Armada y, por último, de las colecciones de atlas, portulanos y derroteros. Finalmente, en 1927 fue creada en el Observatorio una nueva sección, Ilamada Servicio Hidrográfico de la Armada, iniciándose así un período de actividad relacionada con la Hidrografía que se prolongaria hasta finales de 1943, fecha de creación del Instituto Hidrográfico de la Marina en Cádiz, institución de la Armada que desde entonces está al frente de la cartografía náutica española.

Como consecuencia directa de estos antecedentes que acabamos de comentar, el Real Instituto y Observatorio de la Armada conserva en la actualidad una interesante colección de cartografía de los siglos XVIII, XIX y XX. La mayor parte de esta colección está compuesta por cartografía náutica publicada para uso de marinos y navegantes. El resto está formado por cartografía terrestre, principalmente mapas topográficos, militares y geológicos. El catálogo de la colección contiene la descripción de 3.510 unidades cartográficas, aunque muchas de estas descripciones corresponden a atlas o portulanos que contienen numerosas imágenes cartográficas (una vez digitalizada la colección se obtuvieron más de 7.200 imágenes digitales).

Entre los ejemplares más antiguos cabria destacar el atlas titulado Le Neptune François, ou recueil des cartes marines, levées et gravées par ordre du Roy, publicado en París en 1693. Ocupa un sólo registro en el inventario, pero se trata en realidad de una colección compuesta por 23 cartas náuticas de las costas atlánticas europeas (desde el Mar Báltico hasta el Estrecho de Gibraltar). Le siguen en antigüedad dos cartas corregidas por el vicealmirante francés François Olivier, una de ellas perteneciente al Mar Egeo 

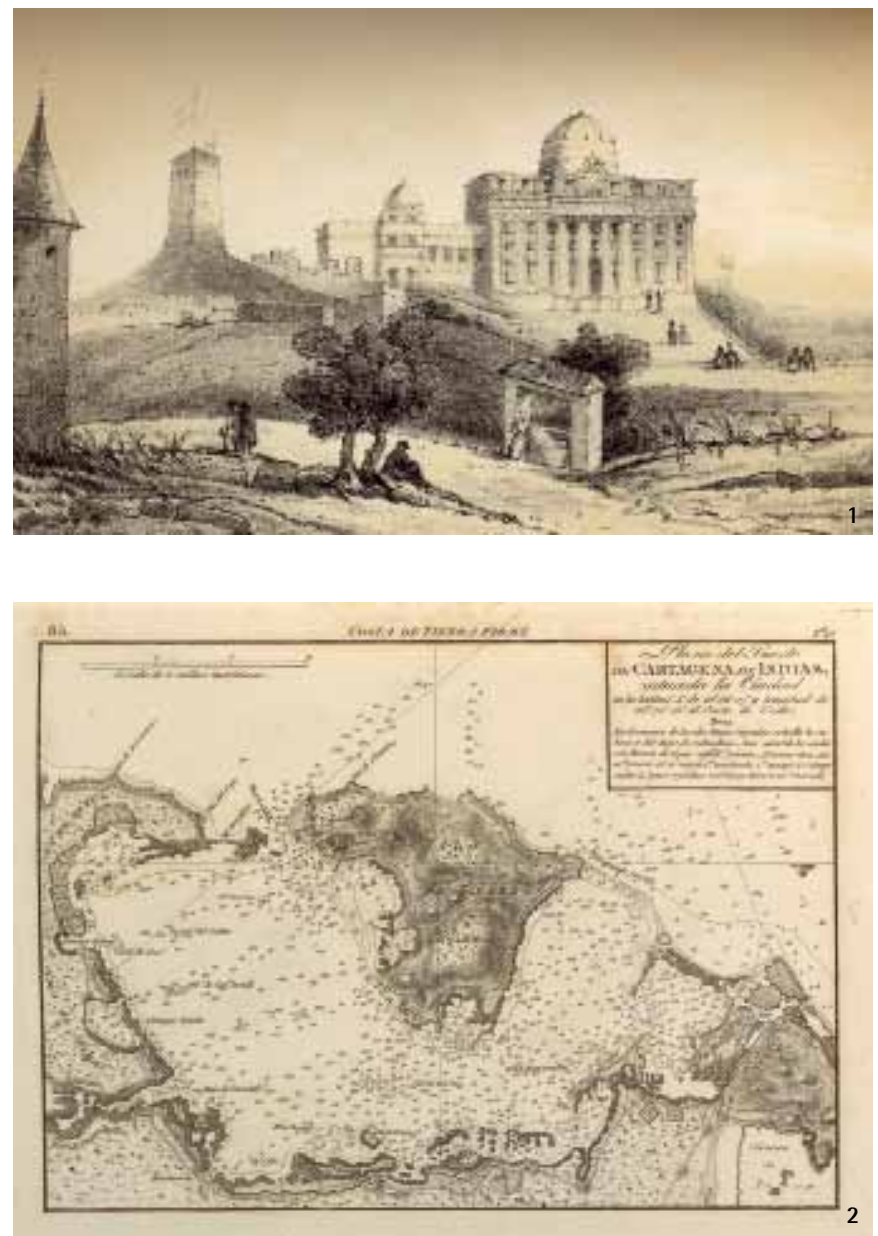

(1746) y la otra referida a la costa atlántica comprendida entre Irlanda y las Islas Canarias (1754). A ellas habría que añadir el Atlas Marítimo de España publicado por Vicente Tofiño en 1789 y una parte importante de la cartografía levantada por las expediciones ilustradas del último tercio del siglo XVIII y por las comisiones hidrográficas del siglo XIX.

La colección cartográfica del Observatorio es complementaria a otras dos importantes colecciones de cartografía náutica conservadas en centros de la Armada, las pertenecientes al Museo Naval de Madrid y al Instituto Hidrográfico de la Marina. Estas tres colecciones forman un conjunto de información cartográfica de carácter hidrográfico que podemos considerar único en España.

El Museo Naval conserva la mayor parte de los fondos de la extinguida Dirección de Trabajos Hidrográficos y posee una interesante colección de cartografia, fundamentalmente manuscrita, generada por las distintas comisiones hidrográficas emprendidas desde el siglo XVIII hasta finales del siglo XIX. Entre las joyas de su colección no podemos dejar de mencionar piezas tan importantes como la famosa carta universal de Juan de la Cosa, realizada en el Puerto de Santa María (Cádiz) en 1500, el portulano del Mediterráneo de Mateo Prunes de 1563 o el atlas de Diego Homen de 1571. La otra institución, el Instituto Hidrográfico de la Marina (Cádiz), que puede ser considerado como el heredero de la tradición hidrográfica

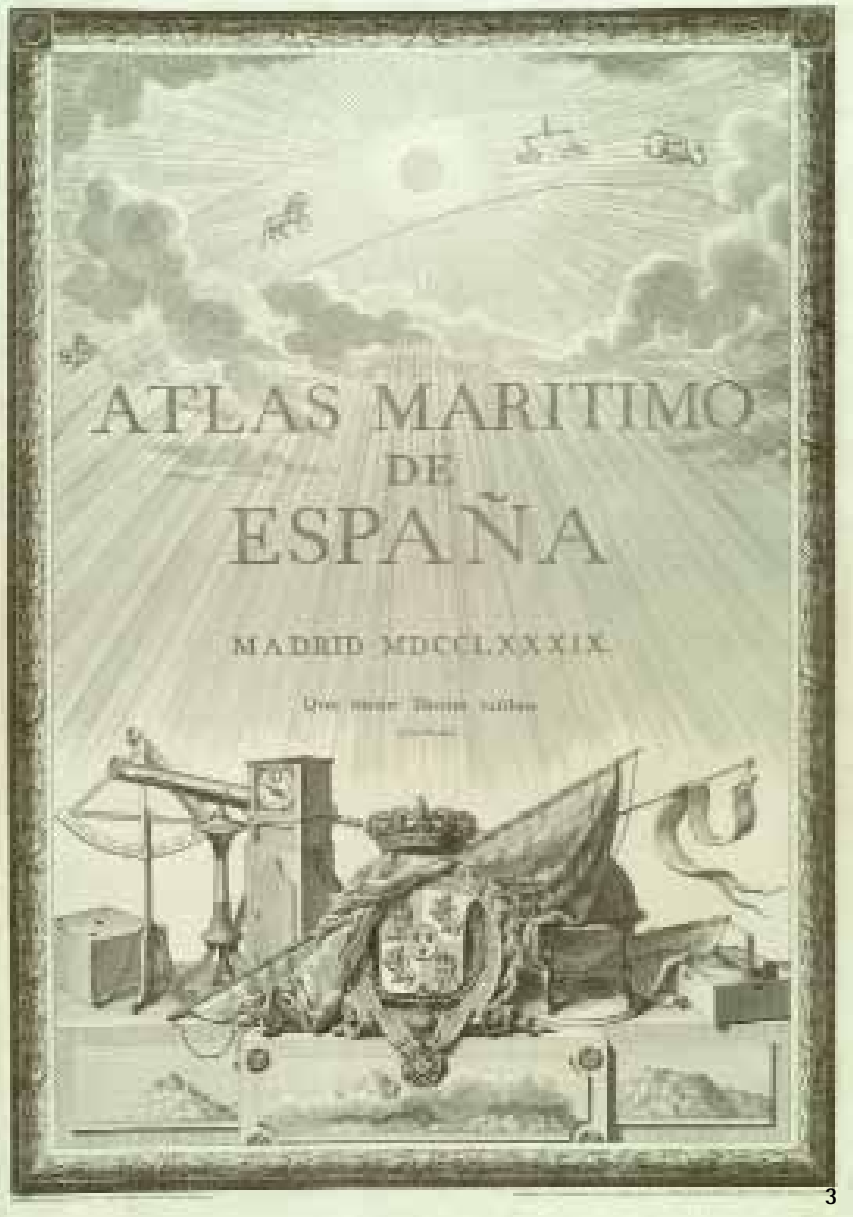

1. El Observatorio de San Fernando a mediados del siglo XIX (Nomenclátor de las Calles de Cádiz de Martín de la Escalera) (Cádiz, 1856).

Fuente: Biblioteca del ROA

2. Plano del puerto de Cartagena de Indias.

Fuente: Colección de Cartografía del ROA. № INV. ROA 2992-19-M

3. Portada del Atlas Marítimo de España (1789).

Fuente: Colección de Cartografía del ROA. № INV. ROA 0428-M y 0430-M

iniciada en el siglo XVIII por la Dirección de Trabajos Hidrográficos, conserva en su archivo una importante variedad de materiales cartográficos integrada por memorias, parcelarios y cartas náuticas, a los que habría que añadir una colección única, la formada por 991 planchas de cobre grabadas en los siglos XVIII, XIX y XX para la impresión de la cartografía náutica oficial española.

\section{Bibliografía}

GONZÁLEZ GONZÁLEZ, F. J. (coord.) (2002) Catálogo de la Colección de Cartografía de la Biblioteca del Real Instituto y Observatorio de la Armada. San Fernando (Cádiz): Real Instituto y Observatorio de la Armada, 2002

GONZÁLEZ GONZÁLEZ, F. J. (2005) El Real Observatorio de la Armada. Madrid: Ministerio de Defensa, 2005

GONZÁLEZ GONZÁLEZ, F. J. (2008) Digitalización de la colección de Cartografía del Real Instituto y Observatorio de la Armada. Revista Catalana de Geografía [en línea], IV època, v. XIII, n. 35 (diciembre 2008) [en línea] <http://www.rcg.cat/ articles.php?id=134> (consulta: 03/11/10)

MARTíN-MERÁS, L. (coord.) (2003) La Dirección de Trabajos Hidrográficos (17971908). Madrid: Ministerio de Defensa, Secretaría General Técnica, 2003, 2 v. 